\title{
Constituição e desenvolvimento do self dialógico e da relação triádica
}

\author{
Maria C. D. P. Lyra ${ }^{a^{*}}$ \\ Letícia Scorsi ${ }^{\mathrm{b}}$ \\ aUniversidade Federal de Pernambuco. Recife, PE, Brasil \\ ${ }^{b}$ Faculdade dos Guararapes, Jaboatão dos Guararapes, PE, Brasil
}

Resumo: Ressaltamos a importância do estudo da gênese do self dialógico. Propomos que esse self emerge e se desenvolve no processo de comunicação em face do Outro. Tendo como foco a história da díade mãe-bebê nos primeiros oito meses de vida do bebê, sugerimos que tanto os padrões de organização do diálogo - atingindo a forma abreviada do diálogo - como a análise das posições que assume a fala da mãe denotam um processo de diferenciação do bebê como parceiro nesse diálogo. Também, o despontar do bebê como agente e sua subjetividade emergem respaldados no desenrolar da historia construída pela díade. Essa historicidade, possível de ser construída através de uma emergente capacidade do bebê de distanciamento e, portanto, capaz de abstrair as ações do contexto imediato no qual ocorrem, se constitui como um terceiro polo do diálogo, formando, então, uma relação triádica.

Palavras-chave: diálogo, tempo, Outro, historicidade, tríade, início da vida.

A teoria do self dialógico (TSD), proposta por Hermans e colaboradores (Hermans, 2001; Hermans \& Kempen, 1993; Hermans, Kempen, \& van Loon, 1992) se desenvolveu, sobretudo, no contexto de estudos em psicoterapia (Hermans \& Dimaggio, 2004; Hermans \& Hermans-Jansen, 1995), abordando, assim, um self maduro, ou seja, um self que já ultrapassou as fases iniciais de seu processo de constituição e desenvolvimento. Tal como nos aponta Bertau (2012), um modelo teórico que inclua e integre o período inicial da vida, do ponto de vista da TSD, ainda necessita ser construído. Assim, o estudo da gênese do self dialógico, investigando os processos que conduzem à sua emergência, é bem-vindo.

Este artigo analisa o processo inicial de constituição do self, abordando a construção das posições de parceiros no diálogo na comunicação entre a mãe e seu bebê do segundo ao oitavo mês de vida do bebê. Assim, contribui para a compreensão do self dialógico na fase inicial de sua constituição e desenvolvimento. $\mathrm{O}$ desenrolar da comunicação mãe-bebê é analisado a partir das transformações que ocorrem na fala da mãe em diálogo com seu bebê. Essas modificações são, também, compreendidas em face do desenvolvimento de padrões de organização dos diálogos na história da díade mãe-bebê (Lyra, 1999, 2007, 2012).

Segundo Valsiner (2007/2012), "A noção de um self dialógico parte de nosso imaginário usual sobre diálogos entre pessoas e é transposta para o diálogo intrapsicológico entre 'partes' do self" (p. 125). Dessa forma, as posições de parceiros Eu-Outro no diálogo podem ser concebidas como a base inicial da qual emerge a diversidade de posições do Eu concebidas na TSD. Ademais, adotamos uma perspectiva que concebe que o bebê nasce imerso em um fechamento dialógico (Bräten, 1998), ou seja, na relação Eu-Outro,

* Endereço para correspondência: marialyra2007@gmail.com requerendo esse Outro, inicialmente de forma física e concreta como parceiro à sua frente (Lyra \& Bertau, 2008). As posições de parceiros no diálogo são, assim, as primeiras posições do self surgindo na e da dinâmica do diálogo no início da vida. Esperamos argumentar que dessa dinâmica emergem, para o bebê, concomitantemente, tanto a posição de parceiro como os primeiros indícios de agentividade e subjetividade, sempre diante do Outro, em um processo conjunto de construção (Lyra, 2007; Lyra \& Bertau, 2008).

\section{A teoria do self dialógico e as posições do Eu: a metáfora espacial, o tempo e o desenvolvimento}

A TSD se fundamenta nas ideias advindas do pragmatismo de James (1980), sobretudo na concepção de um self que excede os limites do corpo e se estende pelo ambiente social que o circunda. Outra fonte de inspiração está na Psicologia Social de Mead (1934), sobretudo com o foco na alteridade e no seu valor constitutivo do self. Particularmente, as ideias de Bakhtin (1934/1981, 1929/1984, 1990) contribuíram para fundamentar uma concepção de self plural que se opõe a um self concebido como unitário, circunscrito nos limites do corpo e da mente. Igualmente, elas ajudaram a inserir o self no contexto sócio-histórico-cultural, semiótico e simbólico, sobretudo por meio do conceito da pluralidade de vozes que habitam e constituem o self, ocupando diferentes posições do eu (I-positions) numa dinâmica de trocas tanto interindividual como intraindividual (Hermans, 2001; Hermans \& Hermans-Konopka, 2010).

Especialmente relevante para a TDS é a noção de posição ou posicionamento em face dos Outros e de si mesmo, compondo uma dimensão espacial que assume o self ao constituir uma sociedade da mente (Hermans, 2002). 
Assim, usando uma metáfora espacial, as diferentes posições do self dialogam, assumindo diferentes vozes, que se confrontam, estabelecem acordos e se modificam, ou resistem à mudança, mas sempre imaginadas como distribuídas em uma paisagem que é espacial (landscape). Sejam internas ou externas, essas posições descrevem os deslocamentos do self nesse espaço, exibindo maior ou menor estabilidade de pontos de vista colocados em ação por meio das diferentes vozes. Essas vozes decorrem dos diferentes grupos que compõem as camadas sociais que coabitam a sociedade e que, segundo Bakhtin (1934/1981), correspondem a diferentes línguas sociais que apresentam direções (ideologias) diversas, disponíveis em dado tempo e espaço. Essa caracterização da natureza social e cultural da diversidade de vozes que dão vida às posições do self nos permite inseri-las na estrutura sócio-histórico-cultural, concebida como um "espaço" tangível que vai compor a sociedade da mente tanto no seu aspecto intersubjetivo como intrasubjetivo.

Todavia, a dialogicidade dessas vozes e, consequentemente, das posições do Eu, requer uma dimensão temporal. Dito de outra forma, requer uma abordagem desenvolvimental do self que possa compreender o movimento transformador dessas posições (Barresi, 2012; Ragatt, 2006, 2012). Mais ainda, requer uma compreensão da sua gênese, ou seja, do seu desenrolar desenvolvimental histórico, desde o momento inicial da vida do sujeito humano. Ademais, o diálogo é um movimento na direção do futuro em tempo irreversível. É preciso lembrar que, para compreender a natureza dinâmica dessas vozes, na heteroglossia que caracteriza a sua coexistência na diversidade de posições do Eu, é preciso compreender tanto o self como a totalidade e as tensões e oposições que desempenham tendências centrifugas e centrípetas, reconhecidas na TSD (Hermans \& Hermans-Konopka, 2010). O self é, portanto, um processo essencialmente dinâmico, perenemente em movimento.

A metáfora espacial possibilita abarcar a multiplicidade de posições e vozes concomitantes, caracterizando não um self unitário, mas plural, assim como um self que excede os limites de corpo e mente isolados. Apesar de conceber essa espacialidade como dinâmica, inerente a uma concepção dialógica (Bakhtin, 1934/1981, 1990, 2003; Hermans, 2001; Hermans \& Hermans-Konopka, 2010; Linell, 2009; Marková, 2003; Salgado \& Hermans, 2005), a TSD dedicou menos atenção ao tempo como transformador, e, consequentemente, o desenvolvimento e os processos de transformação do self mereceram menor destaque nessa teoria (Barresi, 2012; Ragatt, 2006). Faz-se necessário destacar a dimensão tempo, além daquela espacial, e, sobretudo, como esse desenrolar no tempo criando uma história faz emergir, no início da vida, um self dialógico.

Toda essa argumentação em favor da inclusão do tempo ressalta a necessidade de um modelo teórico que abarque o desenvolvimento do self desde o início da vida. Este artigo analisa o processo de emergência do self dialógico se detendo aos primeiros indícios de posicionamento do self, ou seja, à emergência das posições de parceiros no diálogo. Também pretendemos elaborar o argumento de que tanto as características do self enquanto agente como o nascer da sua subjetividade - como uma dimensão interiorizada - emergem conjuntamente às posições de parceiros. Ademais, nos questionamos sobre que papel começa a desempenhar a história construída da díade, no presente caso, a díade mãe-bebê. Comporia essa história um terceiro polo da relação dialógica, constituindo, então, uma tríade?

A ideia de que o diálogo se constitui em uma relação triádica, na qual dimensões de espaço e tempo estão coordenadas compondo um sistema de referência, pode ser atribuída à própria teoria da relatividade de Einstein (Holquist, 2002; Morson \& Emerson, 1990), que Bakhtin (1934/1981) refere como possível metáfora cujos princípios podem ser referidos ao diálogo. Nessa direção, destaca-se que toda relação entre tempo e espaço é, portanto, uma relação mediada por um terceiro que serve de sistema de referência. Nas palavras de Ragatt (2012), "categorias de tempo e espaço são sempre relativas porque elas somente podem ser conhecidas por comparação a conjunto de coordenadas que serve como sistema de referência" (p. 238). A concepção do diálogo como uma relação triádica também é proposto por Marková (2003) e Salgado (2006). Assim, o desenrolar do tempo colocando as suas marcas no processo de desenvolvimento não só é fundamental para a compreensão de um self dialógico como nos sugere considerar esse tempo como criando um terceiro polo do diálogo através da sua historicidade construída.

\section{Posições no diálogo: Eu-Outro}

Qualquer história construída no diálogo é uma história construída com o Outro. A alteridade é ponto central e inicial na constituição do self dialógico. A adoção de uma perspectiva dialógica exige considerar a díade como irredutível, no sentido de que um parceiro existe na dependência do Outro, portanto como interdependentes. A possibilidade de existirem separadamente é excluída dos pressupostos ontológicos e epistemológicos de uma perspectiva dialógica (Bakhtin, 1934/1981, 1990, 2003; Hermans, 2001; Hermans \& Hermans-Konopka, 2010; Linell, 2009; Lyra, 1999, 2007; Lyra \& Bertau, 2008; Marková, 2003; Salgado, 2006; Salgado \& Hermans, 2005). Nessa perspectiva, o processo de comunicação torna-se o locus de emergência, constituição e transformação do self (Bertau, 2008, 2012; Bertau \& Gonçalves, 2007; Fogel et al., 2002; Lyra, 1999, 2007, 2012; Lyra \& Bertau, 2008; Marková, 2003; Salgado, 2006). Inspirado em Bakhtin (1934/1981, 1929/1984, 1993, 2007), Salgado (2006; ver também Ferreira, Salgado, \& Cunha, 2006; Salgado \& Ferreira, 2005) propõe quatro princípios axiomáticos que são perfeitamente coerentes com o que Bertau (2008, 2012), Bertau e Gonçalves (2007), Lyra (1999, 2007, 2012) e Lyra e Bertau (2008) têm proposto, abordando e analisando o início da vida do bebê imerso na comunicação dialógica desde o nascimento. São eles: 
1. O princípio da primazia relacional: a vida humana é sempre uma vida relacional;

2. O princípio da dialogicidade: as relações humanas são relações dialógicas, ou seja, relações com outros seres humanos são relações nas quais esses dois elementos estão circunscritos pela característica de responsividade, criando trocas comunicativas; 3. O princípio da alteridade: consequentemente, a relação dialógica implica a relação com um Outro (pessoa, grupo, comunidade, sociedade) com quem a pessoa se relaciona;

4. O princípio de contextualidade: todas as relações dialógicas ocorrem inseridas em um contexto sociocultural que cria a inteligibilidade específica para as trocas dialógicas. (pp. 55-56, tradução nossa)

Tanto as características de endereçamento (addressivity) como a de responsividade (answerability) são inerentes às trocas dialógicas, adquirindo existência no processo de comunicação. Assim, Marková (2003) destaca que o $\mathrm{Eu}$, a subjetividade, existe apenas imersa no processo de comunicação com o Outro, seja real ou imaginário.

Nessa linha de raciocínio, o mundo dos objetos, o mundo externo, é tomado, também, como um mundo permeado pelo Outro, no qual podemos falar de endereçamento e responsividade tal como nos propõe Moghaddam (2003) ao falar da interobjetividade que inclui o Outro como intermediando as trocas entre parceiros com ou sobre esse mundo. Assim, as trocas mãe-bebê que incluem objetos têm sido conceituadas como mediadas pelo Outro (Lyra, 2007, 2012).

Nesse conjunto de ideias aqui expostas, a investigação da emergência do self no início da vida tem como ponto central de interesse a emergência das posições de parceiros no diálogo. Essas posições antecedem e fornecem as bases sobre as quais irão se diferenciar posições do Eu dotadas das diversas vozes que vão caracterizar o self adulto. A polifonia do self maduro necessita se respaldar nas próprias posições de parceiros no diálogo para que se instaure o endereçamento e a responsividade que estão no cerne da dinâmica do self, e, assim, o lugar do Outro se inaugura. Isso quer dizer que a espacialidade do self habitada pela multiplicidade de vozes é vista, então, através do desenvolvimento histórico no tempo, criando as condições para a dinâmica do diálogo adulto. Tal como nos lembra Valsiner (2004), "a questão crucial da TSD não é reiterar a multivocalidade do self [sua espacialidade], mas a sua estrutura dinâmica" (p. 4, tradução nossa). Nessa direção, a história da emergência e desenvolvimento do self desempenha um papel de destaque na integração do tempo como elemento fundamental para a sua compreensão (Salgado \& Hermans, 2005).

A emergência das posições de parceiros no diálogo inicial (no começo da vida) destaca também o nascimento do self como agente. Essa agentividade é coconstruída a partir da característica de ser parceiro para o Outro e se constituir como capaz de se dirigir a esse Outro (endereçamento) assumindo a sua própria posição no diálogo. Portanto, esse endereçamento implica um agente que é capaz de endereçar e, também, uma semente de subjetividade, desde que o lugar meu e do Outro começam a habitar um espaço sob meu domínio interior, ao construí-lo como minha história.

É justamente nesse ponto que nos questionamos sobre essa história construída: sem ela, não há desenvolvimento. Dela dependem posições, agentividade e subjetividade emergentes. A história se faz pela construção - retomada e reconstrução - de contextos específicos nos quais ocorreram as trocas dialógicas. Nesse sentido, diria respeito ao princípio da contextualidade referido por Salgado (2006) e aqui recuperado como existindo no passado, mas retomado (e reconstruído) no presente. É um porto seguro para o self emergente porque é devido a essa história construída que ele descobre que eu sou o seu parceiro e você é o meu e, mais, eu posso me dirigir a você justamente por isso. Assim, de alguma forma, a história está dentro de mim para que eu a tome como porto seguro (tem de existir um mínimo de segurança para que nela confie, embora possa se tornar seu oposto). A consequência natural desse raciocínio é que a história começa a desempenhar o papel de um terceiro polo do diálogo - um polo de interiorização do Outro que habita dentro de mim - fazendo emergir uma tríade.

Todavia, o que podemos perceber ao acompanhar o raciocínio acima desenvolvido é que parece necessário um quinto princípio axiomático ser acrescentado àqueles propostos por Salgado (2006). Trata-se do principio de historicidade do diálogo que, progressivamente, vai compondo o terceiro polo do diálogo. Esse princípio requer um processo de interiorização e, como tal, exige um grau de distanciamento da experiência imediata para abstraí-la e, assim, reconstruí-la como sua história. Assim, podemos chamá-lo de princípio de historicidade-abstração.

\section{Apropriação do Outro na história construída como compondo um terceiro polo do diálogo: a relação triádica}

A construção da história da comunicação do bebê com seu parceiro adulto nos conduz a compreender que $o$ bebê vai, progressivamente, se apropriando do Outro, do olhar do Outro que subjetivamente passa a habitar o self, e, assim, o constitui. Esses diálogos Eu-Outro ocorrem em contextos socioculturais específicos que vão compondo a história da díade. São como tempos-espaços que pontuam e dão existência a essa história. Nesse sentido, sugere a ideia de cronotopos, tal como referida por Ragatt (2012), a partir da concepção proposta por Bakhtin (1934/1981, 1929/1984, 1990) e destacada por Holquist (1990). Assim, a história passa a desempenhar a função de um terceiro polo na composição dialógica entre os parceiros, agora, então, triádica. O diálogo externo começa a ser construído internamente, 
criando o Outro dentro de mim - e de mim mesmo como self que o criei como agente que sou - na dinâmica processual das trocas dialógicas (Bakhtin, 2007; Salgado, 2006). Nessa mesma vertente, começa a nascer a subjetividade, e, também, a ideia de que sou o autor de minha ação que endereço ao Outro (agentividade).

Dessa forma, enquanto os parceiros constroem e reconstroem suas trocas na ação presente, a história da díade vai sendo criada como respaldo ou suporte para novos diálogos, trazendo-a para o presente e projetando-a no diálogo no futuro. Dessa maneira, sugere um funcionamento abstraído das próprias ações imediatas, internamente construído e ocorrendo paralelo às trocas presentemente acontecendo no diálogo.

Em outros trabalhos, Lyra $(1999,2007,2012)$ e Lyra \& Souza (2003) têm pontuado a importância da abreviação do diálogo mãe-bebê, cujo exemplo mais característico pode ser encontrado na atividade de a mãe oferecer um objeto para o bebê e este o segurar. Essa troca entre os parceiros só adquire esse caráter rápido e imediato abreviado - após um caminho percorrido, no qual as ações de oferecer e segurar foram progressivamente diminuídas, simplificadas e modificadas, e o tempo do diálogo se tornou reduzido. Essa descrição da troca entre os parceiros sugere três aspectos que despontam no bebê e que concebemos como caracterizando o self dialógico emergente: o início de uma interiorização do diálogo, o sentido de endereçamento para o parceiro como agente da ação efetuada e o respaldo em uma história construída que permite reconhecer a forma abreviada como de domínio mútuo, ou seja, partilhada. Destacamos ainda que essa historicidade - que estamos considerando como mais um princípio axiomático do diálogo - requer a capacidade de abstração do contexto imediato das trocas atuais para usar o que foi construído de forma ágil e flexível, tal o faz o bebê, e ser capaz de inovar (sobretudo a mãe, mas, também o bebê) nessas trocas, embora mantendo a forma abreviada (Lyra, 2012).

O desenrolar ontogenético desse desenvolvimento está ilustrado a seguir, primeiramente através da descrição do desenvolvimento dos padrões de organização do diálogo entre a mãe e seu bebê e, em seguida, através das transformações da fala da mãe no desenrolar desse desenvolvimento.

\section{Os padrões de organização do diálogo entre a mãe e seu bebê e as transformações na fala da mãe}

Os dados empíricos aqui apresentados foram obtidos a partir de registros em vídeo do processo de comunicação entre um bebê e sua mãe desde o segundo até 0 oitavo mês de vida do bebê. Esses registros semanais tiveram uma duração em torno de 20 minutos cada.

A análise da fala da mãe, ao longo desses meses iniciais de vida do bebê, foi efetuada considerando dois parâmetros: a posição evidenciada no enunciado, denotando o lugar ocupado pelo parceiro mãe versus o lugar ocupado pelo parceiro bebê, imaginado ou suposto, e o padrão de organização do diálogo mãe-bebê como exibindo três níveis de organização que denotam o desenvolvimento do diálogo.

Classificamos a fala da mãe em três categorias: (a) Fala por Si, (b) Fala pelo Bebê e (c) Fala Combinada. Os padrões de organização compreendem três níveis: (a) Estabelecimento, (b) Extensão e (c) Abreviação (Lyra, 1999, 2007, 2012; Lyra \& Souza, 2003).

\section{Desenvolvimento do diálogo no início da vida: os padrões de organização e a abreviação}

O desenvolvimento do processo de comunicação no início da vida é aqui compreendido como construindo padrões de organização das trocas negociadas pelos parceiros que se desenvolvem e se modificam, culminando na abreviação do diálogo, que ocorre tanto em relação às trocas face a face como àquelas mediadas pelo objeto (Lyra, 1999, 2007; Lyra \& Bertau, 2008; Lyra \& Souza, 2003). Antecedendo o momento da abreviação do diálogo, este se organiza em um primeiro padrão que corresponde ao período de estabelecimento das trocas, seguido daquele chamado de extensão das trocas negociadas. No primeiro, a tarefa da díade é destacar, do fluxo contínuo de ações do bebê, um elemento-ação que possa significar uma estabilidade para deflagrar um diálogo, porque passa a adquirir o caráter de partilhado pela díade. O papel da mãe é dominante, caracterizando a forte assimetria dos diálogos iniciais, mas esta mãe depende do bebê à sua frente, que, tanto física como simbolicamente, é o seu parceiro. Assim, concebemos o estabelecimento como coconstruído pela díade. Este ponto inicial de preparação para o diálogo é referido por Rommetveit (1992) - falando do diálogo adulto - como condição necessária para que qualquer diálogo se inicie. Considerando o diálogo face a face, o contato de olhar e na troca com objetos e a atenção conjunta dos parceiros para um objeto (marcadamente o olhar dirigido para o objeto) constituem a primeira partilha construída pela díade.

O segundo período de organização do diálogo, que chamamos de extensão, compreende o prolongamento do diálogo, que depende do que foi construído como partilhado - o olhar ou a atenção conjunta para o mundo/objeto -, que passa a funcionar como um fundo sobre o qual elementos que compõem as trocas - ações diversas tais como movimentos corporais ou faciais, incluindo sorrisos, e diversos sons por parte do bebê e da mãe, além da fala e qualquer musicalidade - são negociados pelos parceiros.

Segue-se a esse período, a abreviação, que merece uma análise mais detalhada (para exemplos e elaborações ver Lyra, 2007, 2012; Lyra \& Bertau, 2008; Lyra \& Sousa, 2003). Seguindo-se às trocas prolongadas que caracterizam o período da extensão, o diálogo começa a apresentar uma redução em tempo e número de turnos. Os parceiros imediata e facilmente se engajam nessas trocas curtas e as finalizam para se envolverem em outras atividades. Nesses diálogos abreviados, identificamos que tanto a mãe como o 
bebê introduzem novas ações, assim como variações sutis daquelas já conhecidas e de seus ritmos temporais.

Esse padrão abreviado do diálogo possibilita inferir que a díade construiu uma história conjunta que permite ao bebê e à sua mãe dialogarem "com conhecimento mútuo", i.e., um do outro, nessa história conjunta. As consequências dessa construção conjunta permitem a elaboração de três aspectos relativos à constituição de um self dialógico: o primeiro, tanto a mãe como o bebê começam a ocupar seus lugares de parceiros no diálogo; o segundo, esses lugares são ocupados porque os parceiros começam a emergir como agentes da sua ação no diálogo diante do Outro; finalmente, essas características de posicionamento e agentividade são concomitantes ao progressivo conhecimento da história construída, podendo esta ser pensada como catalisadora do aparecimento dos primeiros - ver catalisadoras em Cabell e Valsiner (2014) -, e que passa a desempenhar o papel de um terceiro polo do diálogo, compondo uma tríade - eu-história (Outro dentro de mim)-Outro (Salgado, 2006).

Exemplificando, quando a mãe e o bebê trocam rápidos olhares e sorrisos e se voltam para outra atividade ou quando a mãe oferece um objeto ao bebê e este o segura e, assim, finaliza a troca, esses dois diálogos são abreviados. Só o sabemos em comparação com a não abreviação que o antecede - o período de extensão -, no qual longos períodos de trocas de diversas ações e movimentos eram negociados, mantendo-se o contato de olhar dos parceiros e, com o objeto, observa-se a atenção conjunta para o objeto, com o olhar dos parceiros voltado para o objeto, mas numerosas tentativas para que o bebê o segurasse eram feitas pela mãe ao oferecê-lo, acompanhadas de esforços do bebê para segurá-lo.

O que se observa, então, no diálogo, é que ambos os parceiros se permitem inovar de diferentes maneiras, mantendo a continuidade do diálogo através da manutenção da forma abreviada. Entre as inovações se inclui o bebê "oferecer" o objeto para a mãe, após retê-lo, pois a mãe tenta retirá-lo do bebê, e, depois, deixa-o cair próximo à mãe. Nesses exemplos, em meio a outros, podemos inferir o início de uma posição daquele que dá e daquele que recebe o objeto e, concomitantemente, a produção de uma ação por mim-bebê (agente) dirigida a você parceiro. Essas características denotam o emergir de uma "intencionalidade e agentividade" emergentes ao procurar, o bebê, o contato de olhar face a face com a mãe e, também, terminá-lo para brincar com os objetos.

Aqui desenvolvemos dois argumentos. O primeiro responde à pergunta: que papel desempenha o conhecimento da história para a díade? A análise do diálogo abreviado faz supor que algo começou a ocupar o lugar de um terceiro polo nas trocas entre os parceiros que, então, se projeta em uma dimensão além do imediatamente aqui e agora, propiciando certo distanciamento através de algo "internamente" construído: "sei que vamos continuar a dialogar porque conhecemos este tipo de troca abreviada". Tomemos a inovação paralela à manutenção do diálogo abreviado. A mãe, por exemplo, oferece dois objetos em lugar de um, como era habitual e o bebê segura os dois. $\mathrm{O}$ bebê não solta 0 objeto mesmo que a mãe tente tirá-lo e logo o solta perto da mãe. Em momentos anteriores - durante a extensão - a repetição de um mesmo tipo de troca era o dominante e a inovação era evitada pela mãe - e inexistente da parte do bebê - porque faria acabar o diálogo. Assim, a história construída, que constituiu a forma abreviada do diálogo, passa a desempenhar um papel de terceiro polo que respalda a continuidade das trocas abreviadas. Ambos os parceiros sabem que a forma abreviada permite o desenrolar de um diálogo com variações inovadoras.

$\mathrm{O}$ segundo argumento diz respeito à concomitância da emergência das posições de parceiros no diálogo, da característica de "autor da minha ação" (agente) endereçada ao parceiro e do distanciamento do "imediatamente aqui e agora" ocupando um espaço de alguma forma interiorizado/subjetivo. Todas essas dimensões são aqui sugeridas como emergindo ao mesmo tempo. Elas criam significado quando ancoradas na história da díade. É justamente nesse ponto que ela surge como o terceiro polo do diálogo, compondo uma relação triádica: Eu-Outro-em-mim(História)Outro (Salgado, 2006). Assim, a historicidade-abstração se configura como um quinto princípio axiomático do diálogo.

A seguir, apresentaremos a análise da fala da mãe e de seu paralelismo com os padrões de organização do diálogo até a abreviação dele. Essa fala, ao mesmo tempo em que compõe o diálogo, narra o desenrolar do desenvolvimento do bebê (e dela mesma como parceiro, embora, o nosso foco aqui seja o bebê), no qual podemos reconhecer: os parceiros se diferenciando e exibindo o desenrolar de posições distintas de parceiros assumidas nessa fala; a agentividade do bebê: o bebê cresce como "autor da sua ação"; e o reconhecimento de que, ao longo do tempo, algo foi "aprendido" ou "ficou, de algum jeito, dentro do bebê", i.e. "internalizado", o que permite a "segurança" na história construída, servindo de "porto seguro" a partir do qual inovar e manter o diálogo são possíveis.

\section{Desenvolvimento do diálogo no início da vida: a fala da mãe}

Neste trabalho, a fala da mãe é inserida na organização do diálogo mãe-bebê e dele participando e, assim, denotando o desenrolar do processo de coconstrução do bebê (e de sua mãe) como parceiros no diálogo.

Conforme analisamos em outro trabalho (Scorsi \& Lyra, 2012), encontramos na literatura que, ao longo do processo de comunicação com o bebê, a mãe interpreta os atos deste parceiro e verbaliza tais interpretações (e.g., Lock, 1980). Assim, além de constituir o próprio diálogo, ela também o narra ou descreve do ponto de vista dela como parceiro. Durante o processo de comunicação com o bebê, podemos dizer que ela assume o que chamamos de três diferentes posições de fala, expressas nos enunciados, considerando o lugar dela e do bebê de parceiros no diálogo (Scorsi, 2009; Scorsi \& Lyra, 2004), descritas a seguir.

Fala por Si. A mãe expressa seus próprios desejos, necessidades e pensamentos. Utiliza-se, para isto, de uma 
forma própria de discurso, em que o pronome "eu" se refere à própria mãe e o pronome "você" se refere ao bebê. Ex.: "Eu amo você, viu?" ou "Eu vou trocar sua fralda".

Fala pelo Bebê. Nessa posição, a mãe apropria-se daquela que seria a fala do bebê e expressa desejos, necessidades e pensamentos atribuídos a ele (Griz, Josephs, \& Lyra, 2003). Utiliza-se, para isto, de uma forma de discurso que intenciona reproduzir fielmente o que o bebê estaria dizendo. É como se, num texto escrito, abrisse aspas. Nesse caso, há um deslocamento dos pronomes, em que "eu" se refere ao bebê e "você" se refere à mãe. Ex.: "Eu quero brincar com a minha mãe!" ou "Você fica me enrolando!".

Fala Combinada. A mãe expressa desejos, necessidades e pensamentos atribuídos ao bebê, mas, para isto, utiliza suas próprias palavras. Parece ser uma combinação das falas por si e pelo bebê. Utiliza-se de uma forma de discurso que reporta o que o bebê estaria querendo, sentindo e pensando. Nessa posição, não há deslocamento dos pronomes, mas é como se a mãe colocasse palavras na boca do bebê. Ex.: "Você só quer ficar de pé!" ou "Tá coçando a gengivinha?".

Cabe ressaltar que a classificação das falas da mãe como assumindo uma dessas posições é realizada sempre em relação às ações dos parceiros. Aquilo que o bebê faz (ou deixa de fazer) contextualiza as falas da mãe e nos serve de base para que possamos identificar se uma fala deve ser classificada em uma dessas três posições. Por exemplo, se a mãe diz "Eu tô com sono!", precisamos recorrer ao contexto no qual a fala se insere para podermos identificá-la como pelo bebê ou por si. Na situação desse exemplo, essa fala sucede o fato de o bebê começar a piscar os olhos, sugerindo estar sonolento. Podemos perceber que, nesse caso, a mãe se deslocou de sua posição para a posição do bebê.

Essas posições constituem os enunciados da mãe durante o processo de comunicação com o bebê. Concebemos cada um desses enunciados como coconstruídos na polifonia (Bakhtin, 1934/1981, 2003, 2007), que todo autor carrega, isto é, sua autoria é dividida com outros parceiros além do bebê. Nessa direção, toda a história da mãe e de seu meio social e cultural se faz presente nas suas interpretações do bebê à sua frente. Temos consciência de que as falas da mãe são construídas em coautoria com diversos Outros parceiros, mas, analiticamente, é apenas em relação ao bebê que abordamos essa coautoria. Essa tomada de posição se justifica porque é o aspecto transformador dessa abordagem longitudinal do desenvolvimento do diálogo que estamos enfatizando e é esse desenvolvimento que é objeto deste estudo. Assim, é a coconstrução entre a mãe e seu bebê que está sendo explorada.

Podemos dizer que a fala pelo bebê demonstra um mecanismo para penetrar em seu universo - quem é esse bebê? Ao mesmo tempo, esse bebê é meu "parceiro". Dessa forma, ao longo do tempo, ambos os parceiros vão se diferenciando, e o bebê vai ocupando seu próprio lugar e se tornando cada vez mais ativo no diálogo. Até que ele possa assumir sua própria posição no diálogo, e até que a mãe o perceba como tal, ela assume sua posição. A nosso ver, esse mecanismo tem o papel de apreender e aprender como é o Outro. Tentando se apropriar do lugar do Outro, ela busca conhecê-lo. Concebemos que, através dessa forma dinâmica de trocas, a mãe vai constituindo o bebê como um Outro e, assim, ao lhe dar lugar, ela o coloca em condição de ser alguém a quem ela possa se dirigir, se endereçar.

A fala combinada também representa uma tentativa de apreender o bebê, mas já o reconhecendo como Outro. Seu formato a assemelha ao discurso internamente persuasivo (Bakhtin \& Volochinov, 1992), no qual a autoria é dividida entre o sujeito que fala e seu interlocutor. Por esse motivo, compreendemos essa posição como um tipo mais elaborado de expressão, pois ela parece supor uma maior distinção entre os parceiros.

Sugerimos que a fala pelo bebê é aquela que dá voz ao turno desse parceiro na comunicação. Já a fala por si, tanto externaliza sua voz interna quanto responde ao parceiro. A fala combinada, por outro lado, parece se colocar com uma função que contempla aspectos das duas outras posições. Nessa fala, a mãe verbaliza a sua compreensão do que o bebê quer, precisa, sente, e também responde a ele. Diante disso, entendemos que o uso das diferentes posições ao longo do processo de comunicação com o bebê pode nos informar sobre como ela o reconhece, se mais ou menos ativo e autor da sua ação, mais ou menos independente e capaz de expressar desejos e vontades.

É interessante observar que durante todo o processo de comunicação com o bebê, a mãe assume as três posições de fala, porém, as características delas se alteram ao longo do desenvolvimento e, assim, elas se apresentam diferentes no período do estabelecimento, da extensão e da abreviação.

\section{Descrições e exemplos}

Nesta seção, seguem descrições dessas falas ao longo do tempo, acompanhadas de exemplos que ilustram o que se quer apresentar. Trata-se de um bebê do sexo masculino, cujo nome foi alterado para Mateus.

Fala por Si. A fala por si apresenta uma importante diferença em relação às outras duas posições, pois se refere ao fato de apresentar uma constância quanto aos propósitos principais com que é utilizada (Tabela 1). São eles: responder aos atos ou vocalizações do bebê (exemplo 1); atrair sua atenção (exemplo 2); oferecer-lhe objetos (exemplo 3); estimular-lhe e/ou ensinar-lhe a fazer algo (exemplo 4); narrar o que está fazendo ou o que acontece no ambiente (exemplo 5).

As mudanças nessa posição surgem no período de domínio da extensão e continuam na abreviação, e se referem ao aparecimento das repreensões e dos estímulos para que o bebê faça algo, e também às variações nas tentativas de atrair a atenção do bebê. Assim, um parceiro com novas habilidades, que explora cada vez mais o ambiente e se interessa por coisas outras além da mãe ou do que a mãe lhe oferece, se revela ao longo do tempo. Nesse sentido, a mãe intensifica e diversifica as formas de atrair sua atenção e de estimular-lhe e/ou ensinar-lhe algo. 
Tabela 1

Exemplos de comunicação mãe-bebê da Fala por Si

\begin{tabular}{|c|c|c|c|}
\hline Exemplo & $\begin{array}{l}\text { Idade do bebê (em } \\
\text { semanas) }\end{array}$ & Fala da mãe & Ação do bebê \\
\hline 1 & 6 & Eta, nenê, que fome, hein? & Enquanto mama produz alguns sons. \\
\hline \multirow[t]{2}{*}{2} & 14 & & Olha para o lado. \\
\hline & & $\begin{array}{l}\text { Tá olhando aonde, Mateus? Tá olhando pra } \\
\text { onde, ahn? Psiu. Psiu. }\end{array}$ & \\
\hline \multirow[t]{3}{*}{3} & 29 & [Oferece um objeto para o bebê] Tó! & \\
\hline & & & Quase pega o objeto. \\
\hline & & & $\begin{array}{l}\text { Engatinha na direção do boneco inflável, mas } \\
\text { se distrai com outro objeto. }\end{array}$ \\
\hline \multirow[t]{4}{*}{4} & 30 & $\begin{array}{l}\text { [Oferece novamente o objeto a ele] Toma, } \\
\text { Mateus! } \\
\text { Vai pegar! Vai, mamãe, pegar ela! }\end{array}$ & \\
\hline & & & Volta a engatinhar para o boneco inflável. \\
\hline & & Eita, conseguiu, pega ela, Mateus! & \\
\hline & & Mateus! & \\
\hline \multirow[t]{2}{*}{5} & 27 & & Vocaliza animado. \\
\hline & & $\begin{array}{l}\text { [Tenta prender a chupeta na sua camisa] } \\
\text { Mamãe vai prender aqui! }\end{array}$ & \\
\hline
\end{tabular}

O fato de essa fala apresentar a constância de propósitos acima mencionada é bastante coerente com a posição que a mãe assume ao verbalizá-la. Nessa fala, ela expressa seus próprios pensamentos, desejos e necessidades, questões que se mantêm estáveis, mesmo que ocorram alterações, que podemos chamar de "internas". Explicando melhor, os propósitos com os quais a mãe utiliza essa posição apresentam uma relativa estabilidade; o que se altera é o que ela verbaliza nessa posição, nos diferentes momentos, em função do reconhecimento de transformações no parceiro.

Fala pelo Bebê. Nessa fala, ela assume a posição do bebê para verbalizar aquilo que ele possivelmente diria naquela situação (Tabela 2, exemplo 6). Na extensão, essas falas começam também a servir para que a mãe expresse a voz do bebê nas brincadeiras e para imitá-lo. Já na abreviação, é apenas com esses dois últimos propósitos - expressar a voz do bebê em brincadeiras e imitá-lo - que ela assume essa posição.

Essas transformações indicam que a mãe parece ir deixando de se sentir autorizada a dar voz ao bebê, a não ser em situações específicas que parecem demonstrar mais claramente o papel ativo do bebê ou quando essas envolvem alguma fantasia, como é o caso das brincadeiras (exemplo 7), ou quando ela o reconhece como possuindo voz, e, portanto, é passível de ser imitado (exemplo 8).

Tabela 2

Exemplos de comunicação mãe-bebê da Fala pelo Bebê

\begin{tabular}{|c|c|c|c|}
\hline Exemplo & $\begin{array}{l}\text { Idade do bebê } \\
\text { (em semanas) }\end{array}$ & Fala da mãe & Ação do bebê \\
\hline \multirow{3}{*}{6} & \multirow{3}{*}{7} & & Chora. \\
\hline & & $\begin{array}{l}\text { Tá bom, eu já sei o que você quer! A senhora } \\
\text { fica me enrolando! [oferece o peito ao bebê]. }\end{array}$ & \\
\hline & & & Pega o peito e se acalma. \\
\hline
\end{tabular}


Tabela 2

Continuação

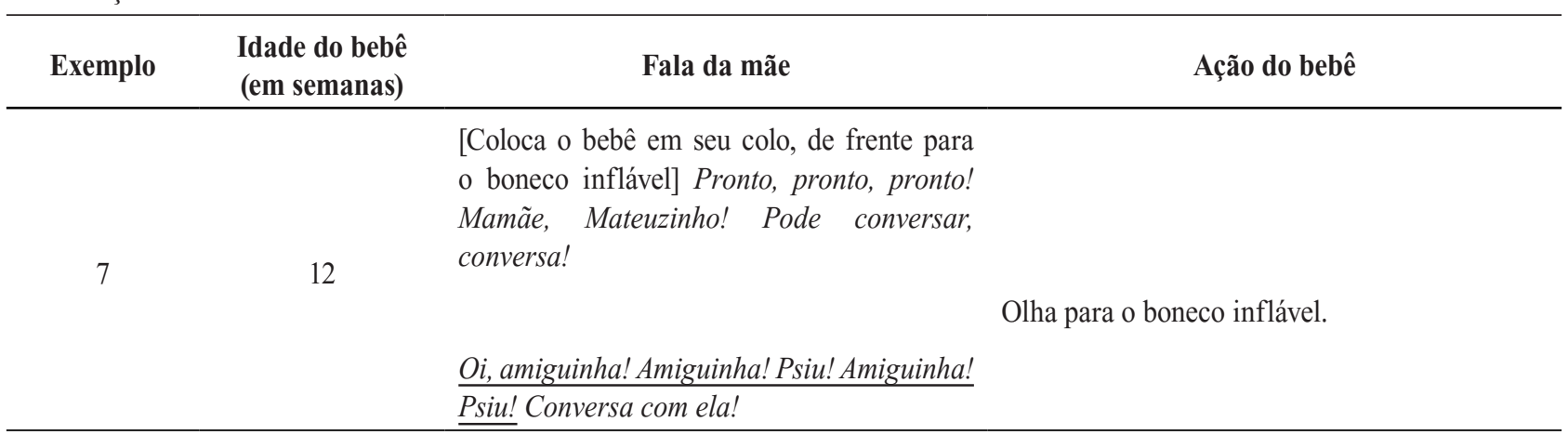

Fica em pé e grita “ah, ta ta ta!".

[Imita o som do bebê] "ah, ta ta ta”, mamãe!

Ruge.

832 [Grita acompanhando os sons do bebê]

"Aaaaaah!".

Olha para a mãe e ruge.

[Grita novamente, acompanhando os sons do bebê] "Aaaaaah!".

A questão da imitação guarda elaborações importantes. Gratier e Trevarthen (2007) afirmam que, quando a mãe imita as vocalizações do bebê, ela reproduz o contorno de entonação e a qualidade da voz do bebê, e, assim, toma a voz do bebê como uma das possibilidades de sua própria voz. A imitação vocal, segundo esses autores, envolve manter um nível de igualdade com a voz do Outro e também introduz uma variação que expressa a troca de sentimentos, autoconfiança e intensidade de propósito. Além disso, a mutualidade e a sincronização de gestos (Brazelton, Koslowski, \& Main, 1974) compõem o todo e as trocas dialógicas se encaixam (Marková, 1990), e, assim, podemos dizer que, mesmo que se tratem de apenas dois turnos (a vocalização do bebê seguida pela imitação da mãe), estes parecem indicar vestígios de uma experiência dialógica que inclui, também, as produções vocais da mãe e do bebê.

Fala Combinada. Em todas as situações em que a mãe assume a fala combinada, ela verbaliza, de sua própria posição, os indícios que percebe do bebê. A evolução nas falas nessa posição se refere tanto a seu conteúdo quanto a opções de cunho gramatical (Tabela 3). Desse modo, temos que, na extensão, enunciados em formato de interrogativas começam a dar lugar a afirmativas, ou afirmativas seguidas de interrogativas (exemplo 9), em que a mãe parece pedir a concordância do bebê. Além disso, no período do estabelecimento, temos falas nessa posição apenas relatando o que a mãe percebe do bebê, mas no período da extensão novos elementos são incluídos a elas, de modo que começam a expressar também atribuições de significados aos atos do bebê, repreensões, críticas ou reclamações sobre ele (exemplo 10). As repreensões ao bebê começam a sofrer elaborações e há a inclusão de diversos novos elementos a essas falas, em que a mãe se refere, por exemplo, a consequências dos seus atos e, muitas vezes, parece expressar surpresa diante de algumas ações do bebê. São esses últimos tipos de fala combinada que encontramos no período de predomínio da abreviação.

Temos que, quando predomina o estabelecimento, a fala combinada se apresenta primordialmente no formato de interrogativas. Isso parece sinalizar a necessidade da mãe de se certificar quanto aos indícios que percebe do bebê. Assim, ora ela parece buscar descobrir o que os indícios oferecidos pelo bebê significam, ora visa confirmar se aquilo que ela interpretou desses indícios está correto.

Quando predomina a extensão, as falas nessa posição apresentam aspectos bastante diversificados. A partir da $12^{a}$ semana, além de verbalizar o que o bebê estaria querendo ou fazendo, a mãe também começa a interpretar o que percebe dele, atribuindo significado aos seus atos. Ou seja, nesse ponto, ela não apenas relata de sua posição os indícios que percebe do bebê, mas adiciona mais elementos a esses relatos, verbalizando também que reconhece sutilezas de seu comportamento. Além disso, falas afirmativas ou interrogativas acrescentadas ao fim de uma afirmação (como se pedisse a concordância do bebê) aparecem nessa posição na $14^{\mathrm{a}}$ e $16^{\mathrm{a}}$ semanas, respectivamente. $\mathrm{Se}$, inicialmente, ela interrogava quanto aos indícios por ele oferecidos, agora ela passa a afirmar sobre eles. Por fim, da $21^{\mathrm{a}}$ semana em diante (fim do domínio da extensão), essas falas passam a verbalizar repreensões, críticas, ou reclamações do bebê, sugerindo que a mãe se vê diante de novas ações desse parceiro. 
Na abreviação, todas as falas combinadas apresentam-se no formato de afirmativas, ou interrogativas acrescentadas ao fim de uma afirmação, e expressam principalmente reclamações do parceiro pelo fato de ele não dar atenção à mãe.

As mudanças referentes a essa fala indicam um parceiro cada vez mais ativo, capaz de ser autor de suas ações, mais independente e com novos interesses e habilidades. Além disso, ao atribuir significados aos atos do bebê e utilizar-se de afirmativas para dizer, de sua própria posição, o que ele pode estar querendo, precisando, ou fazendo, a mãe parece verbalizar um conhecimento mútuo cada vez mais seguro quanto a aspectos trabalhados na história da díade.

Tabela 3

Exemplos e comunicação mãe-bebê da Fala Combinada

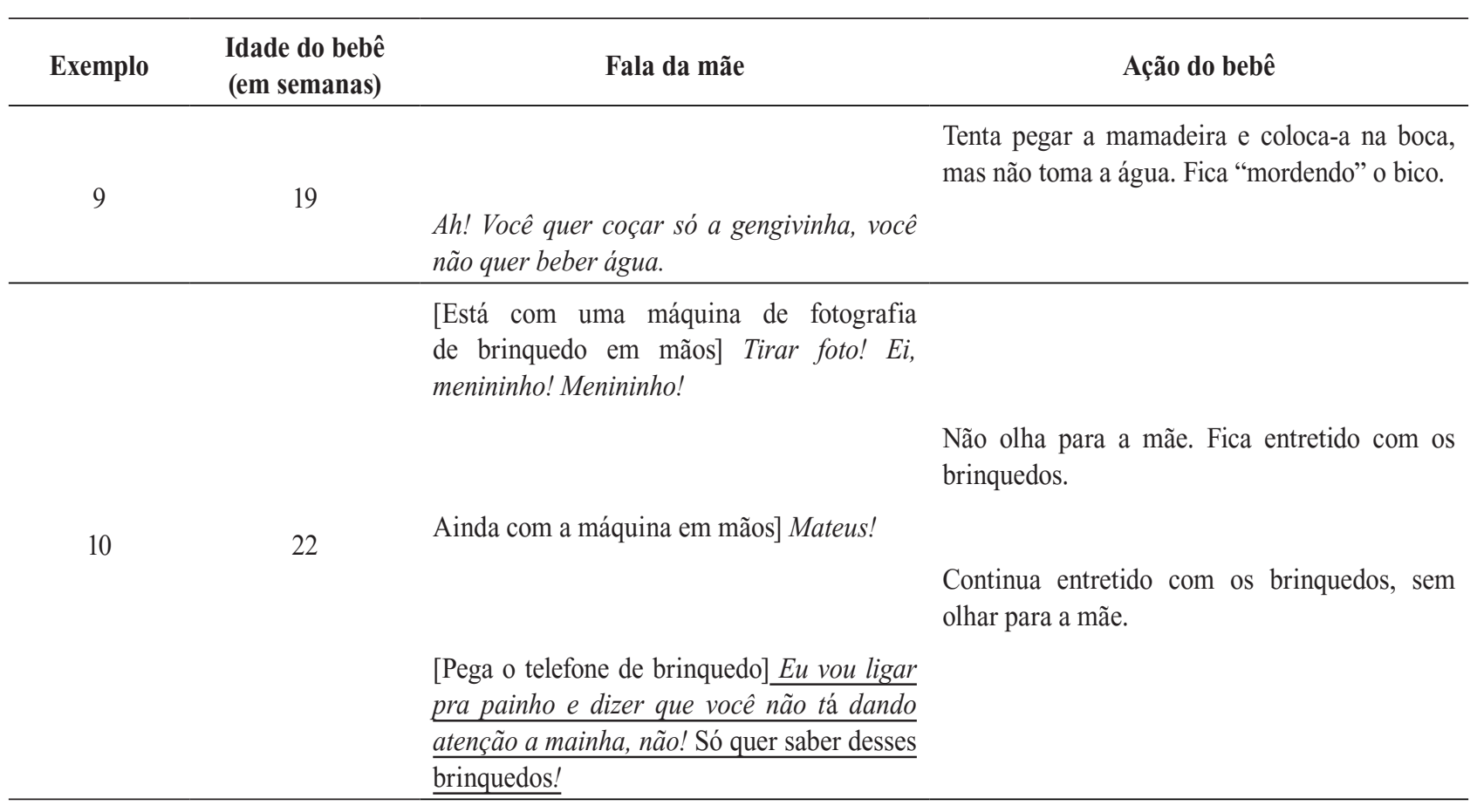

\section{As posições assumidas na fala da mãe e sua coautoria com o bebê}

Ao abordarmos as posições assumidas na fala da mãe, adotamos alguns princípios a respeito dos enunciados - tal como propostos por Bakhtin (1934/1981, 2003, 2007). Primeiramente, todo enunciado é construído conjuntamente com seu destinatário, porque são sempre construídos à expectativa de uma resposta; sempre endereçados a alguém, seja um parceiro real ou imaginário, definido ou não, ativo ou não; o falante define o estilo de seu enunciado de acordo com seu destinatário, sua força e influência e de como o falante o percebe e o representa para si. Tomamos, assim, a coautoria especialmente em relação ao bebê, pois os indícios que o bebê oferece são essenciais para a construção dos enunciados da mãe.

A Fala por Si representa um tipo de enunciado no qual a autoria é compartilhada, particularmente, com outros sujeitos (imaginários pertencentes à história dessa mãe inserida no seu ambiente social e cultural específico), mas, aqui, elas evidenciam a sua relação com as situações vivenciadas com o parceiro bebê. Por outro lado, a Fala pelo Bebê apresenta uma coautoria ainda mais circunscrita à relação com esse parceiro, uma vez que ela dá voz ao bebê por meio da sua fala, assumindo a posição dele no diálogo. Nesse tipo de fala, a mãe destaca a autoria do bebê e seu papel no diálogo. O estilo dessas falas parece indicar uma identificação da mãe com o bebê, conforme observado por Cavalcante (1999). Assim, a fala pelo bebê demonstra um mecanismo para conhecê-lo (por meio da identificação com ele), uma forma de tentar penetrar em seu universo, mais do que meramente uma apropriação da voz do Outro. A Fala Combinada, por sua vez, reflete também uma tentativa de penetrar no universo do parceiro, mas fazendo-o de sua posição. Ela se assemelha ao discurso internamente persuasivo (Bakhtin \& Volochinov, 1992), aquele que é "metade nosso, metade do Outro", e parece indicar que a mãe está diante de um parceiro a ser conhecido, porém, identificando-o como Outro.

Podemos dizer, portanto, que a maneira como a mãe se dirige a seu parceiro indica como ela o reconhece. Ou seja, inicialmente, como um parceiro que ela desconhece, concebendo-o como "menos capacitado de ser parceiro independente de mim". À proporção que o bebê se desenvolve, a mãe vai instituindo o lugar do bebê como parceiro, diferente e distinto dela mesma. Nesse sentido, destacamos 
dois pontos a respeito das transformações nas posições ao longo do tempo: as novidades sendo constantemente introduzidas e a segurança quanto ao conhecimento de aspectos previamente trabalhados - i.e., a história construída começa a emergir como um terceiro polo no diálogo, sugerindo uma relação triádica. Esses pontos nos permitem afirmar que a fala da mãe indica que ela reconhece estar diante de um parceiro que, ao longo do tempo, vai se mostrando mais ativo, mais independente e mais dono do seu próprio lugar no diálogo. O conhecimento dessa história como partilhada permite que as trocas que ocorrem no período de domínio da abreviação apresentem flexibilidade para inovar e, assim, incluir novos elementos de negociação no diálogo, características peculiares a esse período, descritas por Souza e Lyra como "explosão para o novo" (Lyra \& Souza, 2003; Souza \& Lyra, 2001).

\section{As posições da fala da mãe e os padrões de organização do diálogo}

É importante destacar que as falas da mãe, em termos das posições assumidas na sua trajetória de desenvolvimento, exibem um paralelismo com o desenvolvimento do processo de comunicação entre os parceiros, seus padrões de organização, e, dessa forma, também os compõem. Assim, quando a comunicação está sendo estabelecida, elementos mais restritos são verbalizados e a busca por conhecer o parceiro é mais intensificada do que nos períodos seguintes. Quando essa comunicação começa a ser estendida, há uma mistura de elementos, em que tanto algum conhecimento já se estabeleceu como outros conhecimentos ainda precisam de elaboração. Além disso, a fala da mãe se relaciona à forma extensa das trocas e apresenta uma gama maior de elementos trabalhados. Por fim, quando a comunicação já é passível de ser abreviada, também a fala da mãe reflete esse movimento, apresentando menos elementos verbalizados e indicando que o conhecimento mútuo já se faz seguro em relação a alguns aspectos. Mas, nesse período, ela abre também novas possibilidades que se fazem perceber nas novidades que continuam sendo verbalizadas. Esse aspecto é bem característico da abreviação, que é justamente o momento em que cada parceiro começa a assumir o seu próprio lugar no diálogo. Assim, entendemos que a fala da mãe narra o processo de diferenciação das posições dos sujeitos como parceiros, ao mesmo tempo em que também constitui esse diálogo.

\section{Conclusão}

Neste trabalho, destacamos a necessidade de atentar para o tempo, ou seja, a dinâmica que possibilita a transformação e o desenvolvimento de um self estendido no espaço e composto de uma diversidade de posições do Eu. Assim, procuramos ressaltar a importância do estudo da gênese do self dialógico. Apresentamos um self que, progressivamente, diferencia a posição de parceiro no diálogo, ao mesmo tempo em que desenvolve sua característica de agente. Além disso, a construção da sua história, criando a historicidade do self, concebida como princípio axiomático, sugere uma dimensão de interiorização e subjetivação através da nascente característica de distanciamento do aqui e agora e, portanto, demonstrando as sementes de uma capacidade nascente de abstração. Principalmente, propusemos ser a história construída - no presente caso, ilustrada através da história da díade mãe-bebê durante os oito primeiros meses de vida do bebê - um terceiro polo do diálogo, compondo, então, uma tríade, cuja ontogênese se dá em face do Outro.

\section{Emergence and development of the self and the triadic relationship}

Abstract: This work highlights the importance of the study of the genesis of the dialogical self. We assume a perspective that this self emerges and develops immersed in the communication process facing the Other. Focusing on the history of motherinfant dyad during the first eight months of the infant's life, we suggest that both the pattern of organization of the dialogue, achieving an abbreviated form, and the analysis of the mother's speech exhibit a process of differentiation of the infant as a dialogical partner. Moreover, simultaneously appear the rise of agentivity and subjectivity of the infant, anchored by the growth of the history constructed by the dyad. This historicity, allowable by the emergent infant's capacity for distancing from the here and now of actions, appears as a third pole of the dialogue, constituent, thus, a triadic dialogical relationship.

Keywords: dialogue, time, Otherness, historicity, triad, early life.

\section{La constitution et développement du self et de la relation triadique}

Résumé: Cet article souligne l'importance de l'étude de la genèse du self dialogique. Nous proposons que ce self émerge et se développe dans le processus de communication face à l'Autre. En focalisent l'histoire de la dyade mère-bébé dans les huit premiers mois de la vie de celui-ci, nous suggérons que les modèles d'organisation du dialogue - lesquels comprennent la forme abrégée du dialogue -, aussi bien que l'analyse des positions qu'assume le parler de la mère, dénotent un processus de différentiation du bébé comme partenaire dans le dialogue. En outre, l'éveil du bébé comme agent dans ce dialogue et sa subjectivité trouvent appui dans le déroulement de l'histoire construite par la dyade. Cette historicité, dont la construction est 
rendue possible par la capacité du bébé de commencer à se distancer et, dès lors, d'abstraire les actions du contexte immédiat dans lequel elles se produisent, constitue un troisième pôle du dialogue et forme ainsi une relation triadique.

Mots-clés: dialogue, temps, Autre, historicité, triade, début de la vie.

\section{Formación y desarrollo del self dialógico y de la relación tríada}

Resumen: Este ensayo señala la importancia del estudio del self dialógico. Proponemos que ese selfsurge y tiene su desarrollo en el proceso de comunicación hacia otra persona. Desde la historia de la díada madre hijo en los primeros ocho meses de vida del nene, consideramos que tanto los estándares de organización dialógicos — llegando a la forma abreviada del diálogo — como el análisis de las posiciones que asume el habla de la madre denotan un proceso de diferenciación del nene como compañero en ese diálogo. También, cuando el nene surge como agente y con su subjetividad garantiza el desarrollo de la historia construida por la díada. Esa historicidad, posible de ser construida a través de una emergente capacidad del nene en alejarse y, siendo así, capaz de abstraer las acciones del contexto inmediato en la cual ocurre, forma un tercer polo de diálogo, construyendo, así, una relación tríada.

Palabras clave: diálogo, tiempo, Otro, historicidad, tríada, inicio de la vida.

\section{Referências}

Bakhtin, M. M. (1981). The dialogical imagination: four essays by M. M. Bakhtin (C. Emerson \& M. Holquist, trad.). Austin, TX: University of Texas Press. (Trabalho original publicado em 1934)

Bakhtin, M. M. (1984). Problems of Dostoevsky's poetics (C. Emerson, trad.). Minneapolis, MN: University of Minnesota Press. (Trabalho original publicado em 1929)

Bakhtin, M. M. (1990). Art and answerability (V. Liapunov, trad.). Austin, TX: University of Texas Press.

Bakhtin, M. M. (1993). Toward a philosophy of the act (M. Holquist \& V. Liapunov, Orgs.) (V. Liapunov, trad.). Austin, TX: University of Texas Press.

Bakhtin, M. M. (2007). Speech genres and other late essays. Austin, TX: University of Texas Press.

Bakhtin, M. M., \& Volochinov, V. N. (1992). Marxismo e Filosofia da Linguagem. São Paulo, SP: Hucitec.

Barresi, J. (2012). Time and the dialogical self. In H. J. M. Hermans \& T. Gieser (Orgs.), Handbook of dialogical self theory (pp. 46-63). Cambridge, UK: Cambridge University Press.

Bertau, M. C. (2008). Voice: A pathway to consciousness as "social contact to oneself". Integrative Psychological and Behavioral Science, 42(1), 92-113.

Bertau, M. C. (2012). Developmental origins of dialogical self: Early childhood years. In H. J. M. Hermans \& T. Gieser (Orgs.), Handbook of dialogical self theory (pp. 64-81). Cambridge, UK: Cambridge University Press.

Bertau, M. C., \& Gonçalves, M. (2007). Looking at "meaning in movement" in development: Introductory reflections on the developmental origins of the dialogical self. International Journal for Dialogical Science, 2(1), 1-13.

Bräten, S. (1998). Intersubjectivity communion and understanding: Development and pertubation. In S. Bräten (Org.), Intersubjectivity communication and emotion in early ontogeny (pp. 372-382). Cambridge, UK: Cambridge University Press.

Brazelton, T. B., Koslowski, B., \& Main, M. (1974). The origins of reciprocity: the early mother-infant interaction. In M. Lewis \& L. A. Rosenblum (Orgs.), The origins of behavior: The effect of the infant on its caregiver (Vol. 1, pp. 49-76). Princeton, NJ: John Wiley \& Sons.

Cabell, K. R., \& Valsiner, J. (2014). The catalyzing mind: beyond models of causality. New York, NY: Springer.

Cavalcante, M. (1999). Da voz à língua: a prosódia maternae o deslocamento do sujeito na fala dirigida ao bebê (Tese de doutorado). Universidade Estadual de Campinas, Campinas.

Ferreira, T., Salgado, J., \& Cunha, C. (2006). Ambiguity and the dialogical self: In search for a dialogical psychology. Estudios de Psicologia, 27(1), 19-32.

Fogel, A., De Koeyer, I., Bellagamba, F., \& Bell, H. (2002). The dialogical self in the first two years of life. Embarking on a journey of discovery. Theory \& Psychology, 12(2), 191-205.

Gratier, M. E., \& Trevarthen, C. (2007). Voice, vitality and meaning: on the shaping of the infant's utterances in willing engagement with culture. Comment on Bertau's "On the notion of voice". International Journal for Dialogical Science, 2(1), 169-181.

Griz, S., Josephs, I., \& Lyra, M. C. P. (2003). I-positions assumed by the mother in a mother-infant interaction. Manuscrito não publicado.

Hermans, H. J. M., \& Dimaggio, G. (Orgs.). (2004). The dialogical self in psychotherapy. Hove, East Sussex, UK: Brunner-Routledge.

Hermans, H. J. M., \& Hermans-Konopka, A. (2010). Dialogical self theory. Cambridge, UK: Cambridge University Press.

Hermans, H. J. M., \& Kempen, H. J. (1993). The dialogical self: meaning as movement. San Diego, CA: Academic Press. 
Hermans, H. J. M. (2001). The dialogical self: toward a theory of personal and cultural positioning. Culture \& Psychology, 7(3), 243-281.

Hermans, H. J. M. (2002). The dialogical self as a society of the mind: introduction. Theory \& Psychology, 12(2), 147-160.

Hermans, H. J. M., \& Hermans-Jansen, E. (1995). Selfnarratives: the construction of meaning in psychotherapy. New York, NY: Guilford.

Hermans, H. J. M., Kempen, H. J., \& van Loon, R. (1992). The dialogical self: beyond individualism and Racionalism. Americam Psychologist, 47, 23-33.

Holquist, M. (1990). Dialogism: Bakhtin and his world. New York, NY: Routledge.

Holquist, M. (2002). Dialogism (2a ed.). Londres, UK: Routledge.

James, W. (1980). The principles of psychology. Londres, UK: MacMillan.

Linell, P. (2009). Rethinking language, mind and world dialogically: interactional and contextual theories of human sense-making. Charlotte, NC: Information Age Publishing.

Lock, A. (1980). The guided reinvention of language. London, UK: Academic Press.

Lyra, M. C. D. P. (1999). An Excursion into the dynamics of dialogue: Elaborations upon he dialogical self. Culture \& Psychology, 5(4), 477-489.

Lyra, M. C. D. P. (2007). On abbreviation: dialogue in early life. International Journal for Dialogical Science, 2, 15-44.

Lyra, M. C. D. P. (2012). Self and symbols emerging from dialogical dynamics. In M. C. Berta, M. M. Gonçalves \& P. T. H. Ragatt (Orgs.), Dialogical formations Investigation into the origins and development of the dialogical self(pp. 212-144). Charlotte, NC: Information Age Publishing.

Lyra, M. C. D. P., \& Bertau, M. C. (2008). Dialogical practices as basis for self. Studia Psychologica, 8, 173-193.

Lyra, M. C. D. P., \& Souza, M. (2003). Dynamics of dialogue and emergence of self in early communication. In I. Josephs \& J. Valsiner (Orgs.), Dialogicality in Development (Vol. 5, pp. 51-68). Greenwich, CT: Ablex Publishing Corporation.

Marková, I. (1990). A three-step process as a unit of analysis in dialogue. In I. Marková \& K. Foppa (Orgs.), The Dynamics of Dialogue (pp. 129-146). New York, NY: Springer-Verlag.

Marková, I. (2003). Dialogicality and social representation. Cambridge, UK: Cambridge University Press.

Mead, G. H. (1934). Mind, self and society. Chicago, IL: University of Chicago Press.

Moghaddam, F. M. (2003). Interobjectivity and culture. Culture \& Psychology, 97, 315-331.

Morson, G. S., \& Emerson, C. (1990). Mikhail Bakhtin: creation of a prosaics. Stanford, CA: Stanford University Press.
Ragatt, P. T. F. (2006). Multiplicity and conflict in the dialogical self: a life-narrative approach. In D. P. MacAdams, R. Josselson, \& A. Lieblich (Orgs.), Identity and story: The narrative construction (pp. 15-35). Washington, DC: American Psychological Association.

Ragatt, P. T. F. (2012). Personal chronotopes in the dialogical self: a developmental case study. In M. C. Berta, M. M. Gonçalves \& P. T. H. Ragatt (Orgs.), Dialogical formations - investigation into the origins and development of the dialogical self (pp. 235-250). Charlotte, NC: Information Age.

Rommetveit, R. (1992). Outlines of a dialogically based social-cognitive approach to human cognition and communication. In A. H. Wold (Orgs.), The dialogical alternative: towards a theory of language and mind (pp. 19-44). Oslo, Noruega: Scandinavian Press.

Salgado, J. (2006). The feelings of a dialogical self: affectivity, agency, and otherness. In L. Mathias \& J. Valsiner (Orgs.), Otherness in question. Labyrinths of the self (pp. 53-71). Charlotte, NC: Information Age Publishing.

Salgado, J., \& Hermans, H. J. M. (2005). The return of subjectivity: from a multiplicity of selves to the dialogical self. Electronic-Journal of Applied Psychology, 1, 3-13.

Salgado, J., \& Ferreira, T. (2005). Dialogical relations as triads: implications for the dialogical self theory. In P. K. Oles, H. J. M. Hermans (Orgs.), The dialogical self: Theory and research (pp. 141-152). Lublin, Polônia: Wydawnictwo KUL.

Scorsi, L., \& Lyra, M. C. D. P. (2004). Posições no diálogo: a fala da mãe e o desenvolvimento do sistema de comunicação mãe-bebê. In XXXIV Reunião Anual da Sociedade Brasileira de Psicologia, Ribeirão Preto, São Paulo.

Scorsi, L. (2009). A fala da mãe no processo de diferenciação dos sujeitos (Tese de doutorado). Programa de Pósgraduação em Psicologia Cognitiva, Universidade Federal de Pernambuco, Recife.

Scorsi, L., \& Lyra, M. C. D. P. (2012). O manhês e o desenvolvimento da comunicação adulto-bebê. Interação em Psicologia, 16(2), 293-305.

Souza, M. S., \& Lyra, M. C. D. P. (2001). Development of early communication: contributions from a dynamic, historical, and dialogical approach. In III Conferência de pesquisa sócio cultural, Campinas, São Paulo.

Valsiner, J. (2004). Temporal integration of structures within the dialogical self. In III International Conference on the Dialogical Self, Varsóvia, Polônia.

Valsiner, J. (2012). Fundamentos da psicologia cultural: mundos da mente mundos da vida. Porto Alegre, RS: Artmed. (Trabalho original publicado em 2007)

Recebido: $20 / 01 / 2015$

Revisado: 22/03/2016

Aceito: $26 / 04 / 2016$ 